\title{
Would I lie to you? Researching audience attitudes to, and uses of, the promotional trailer format
}

Frederick L. Greene University of California

Keith M. Johnston University of East Anglia

Ed Vollans University of East Anglia

\section{Introduction}

Almost 100 years ago, E. Winthrop Sargent noted that 'One of the best, cheapest and most direct forms of advertising to patrons[...] is by means of the [cinema] screen' (Sargent 1915: 50). Since that time, arguably the most potent realization of his claim has been the 'coming attraction' film trailer. From 'flashing a few scenes to stimulate curiosity in a coming production' ('Selznick Has Clever Trailer’ 1917: 663) to a selection of 'interesting and colourful highlights' (Lasky 1938: 13) edited together as 'bait' to attract an audience (Lewis 1933: 248), the trailer has become one of the most successful and influential advertising formats across media. Yet from those formative years until the present day, the trailer itself has accrued as much negative publicity as positive: trailers were regularly described as misleading (Lewis 1933: 249; Thompson 1937: 7; Goldwyn 1951: 100), as being 'too genteel' and requiring renovating (D.W.C. 1938: 4) or as 'pumped-up bullies, yelling out torrents of abuse' (Medhurst 1998: 24). This historical context goes some way to explaining the glee found in more recent newspaper reports headlined 'Woman sues to stop Drive getting away with a "Misleading” trailer' (Child 2011) or 'Jack Reacher film gives New Zealand viewer too little bang for his buck' (2013): popular discourse around the trailer is based almost wholly on claims of misrepresentation and textual reliability in relation to its big brother, the feature film. 
Yet this perspective is not dissimilar to academic work on the topic, which places particular value on the fidelity of the trailer-film relationship (Gray 2010; Haralovich and Klaprat 1981/2; Kernan 2004). Theoretical trailer studies have tended to focus on trailer aesthetics in relation to its idealized use, rather than assessing the audience opinion of the trailer, the context in which trailers are viewed and the purposes to which they may be put; equally, while one limited sector of the audience has been studied in relation to fan-produced trailers, such work tends towards the utopian or participatory trend within studies of computerized media (Hesford 2013; Williams 2009). Overall, the interest in trailer structure and content has overshadowed the role of the audience, and the creative processes involved in creating the trailer, resulting in the implicit assumption that all trailers are the same in construction, reception and purpose. Most academic studies also operate under the same assumption as popular discourse, which is that 'trailer' is a comprehensible title that signifies both the textual characteristics of the media text and its intended use, and which separates 'trailer' (a term adopted across multiple media: Johnston 2009; Vollans 2013) from other audio-visual promotional short films. As popular and academic work on trailers has shown (Johnston 2004; 'Specialised Techniques in Trailer Production' 1938), the absence of solid definition often makes it unclear where the boundaries of the term 'trailer' are (cf. Maier 2009; Kernan 2004; Johnston 2008).

The absence of the audience in trailer studies, as suggested here and outlined in more detail below, contributed to the authors' decision to jointly design and implement a multistage project into trailer viewing practices. Launched in December 2013, the project will combine qualitative and quantitative approaches to consider how audiences use trailers, the social and economic processes that surround them, and the expectations viewers have of the trailer format. As the initial survey ended shortly before the time of writing, it would be premature to speculate upon any initial results (these will appear via 
www.watchingthetrailer.com). The following develops the rationale and justification for this study, its place within the wider research context and some initial thoughts about future pathways for research.

\section{Trailer: Theory and practice}

While the field of trailer studies may have expanded in the last decade, it remains underdeveloped despite the trailer's status as a unique and neglected resource within media studies. Unlike a feature film or a television programme, around which claims of artistry have been made, the trailer is often reduced to an ephemeral form, an unsigned, transient piece of media, its existence traditionally defined by temporal and spatial circumstances, and with a limited perception of function: as a persuasive text that manipulates the audience into buying products. When trailers have been defined explicitly within the available literature, it is as short as persuasive films (Kernan 2004), propaganda (Greene 2013) or film advertising (Blandford et al. 2001; Konigsberg 1988): a definition that has made it into aspects of legal regulation (Ontario Regulation 452/05).

Outside the issues of definition however, the trend in theoretical studies of the trailer has been to focus on the assumption of persuasion and effect over actual audience decision making. Setting off the trend in persuasive trailer studies, Mary Beth Haralovich and Cathy Root Klaprat describe the trailer as repackaging the narrative of a film, presenting 'in 90 seconds the material that films will take 90 minutes to work over' (1981/2: 65). They note that any changes made between the trailer and feature film narratives are to create in the audience 'the desire to buy a ticket' (1981/2: 66). Two decades later, and expanding upon this theme, Lisa Kernan's rhetorical study of the trailer linked narrative structure to audience appeal, a persuasive formula that allows 'audiences to create an imaginary (as-yet-unseen) film out of these fragments - we desire not the real film but the film we want to see' (2004: 
13). Both these understandings suggest a positive (if unproven) engagement on the part of the audience with the trailer, assuming that the audience will construct an unseen film that they wish to see, rather than being dissuaded by the information contained within a trailer. ${ }^{12}$

As is clear from that work, most trailer studies literature follows Kernan's claim that a trailer is 'is created for the purpose of projecting in theaters to promote a film's theatrical release' (2004: 1). This leads to a tendency to consider only one, temporally disingenuous, viewing relationship between the trailer and the film: namely, that the trailer is viewed first, then the film. The confinement of the trailer to a specific temporal and spatial understanding limits the understanding of the trailer to an a priori one. Such considerations of a trailer's success and appeal are not drawn from sales figures, empirical audience responses or wider research into trailer use, and threaten to subordinate the trailer to an adjunct of the feature film viewing experience. Yet this temporal subordination has a further impact: any analysis that judges the trailer as a re-configuration of the larger and dominant film text to which it relates insists upon a retroactive position from which to judge the trailer and the product it is promoting. To be clear, judging the relationship between the film Marked Woman (Bacon, 1937) and the Marked Woman trailer (as in Haralovich and Klaprat 1981/2) is methodologically complex, as such analysis necessarily speaks from a position of omniscience, knowing both the trailer and the film itself, and not speaking from the position of an unknowing or unassuming audience. In short, the established theoretical view of the trailer as persuasive has to fix the order in which audiences may encounter the trailer and the film, marginalizing the impact of changes in viewing habits and contexts over time.

Keith M. Johnston (2008: 145) has sought to refocus trailer studies by suggesting that previous literature limits 'what trailers are, what they can mean, who they target, and why we should be interested in them'. By recognizing that there is a wider structural variety to trailers, that these 'coming attractions' can change function over time and in different contexts, 
Johnston suggests trailers should be considered instead as short films, echoing some of the earliest understandings of the trailer (Staiger 1990: 26). By reducing the reliance upon a set purpose (selling a film), and the a priori determinism found therein, and by reconsidering the basic approach to trailer studies, Johnston throws the onus of trailer understanding onto the audience. This conceptualization better accounts for the rise of other forms of film trailer across different media (the television trailer, the Internet trailer), yet also raises the question of the distinction between other short form audio-visual texts (Vollans 2013). The as yet unaddressed equivalency between trailers and other short films (including other kinds of trailers) offers one potential goal for audience-led research which can move beyond a priori terms and goals that limit the findings of contributions in this area.

\section{Audience studies and the trailer}

As a result of the slow development of trailer studies, and the existing emphasis on the trailer's industrial and ephemeral nature, few studies have explored how and why trailers may be encountered by audiences, or the context in which individuals use trailers. While we have discovered one attempt to investigate audience responses to different types of trailers (Eastman et al. 1985), and several audience studies that touch upon the trailer as a key influence in movie-going decision making (see, e.g. Austin 1981; Faber and O’Guinn 1984; Yousry 2010), these provide only a fragmented, partial view of the trailer's role within contemporary culture. While trailer focus group sessions are regularly conducted by the film industry, we were aware that such 'commercially sensitive research has left few traces in the scholarly literature' (Davis et al. 2013: 2), speaks only to a single cohort and functions in a potentially artificial environment. Equally, the recent use of large-scale case studies that explore fan engagement with different kinds of promotional material offer a partial expansion of the field, but such work tends to focus on viewers of a specific film or franchise (e.g. Biltereyst et al. 2008; Davis et al. 2013). While these studies found trailers as a useful text 
within specific audiences' information gathering processes (often finding the trailer more useful than other materials), the research did not consider broader attitudes to the trailer, or why such fan groups perceived promotional materials as useful. The absence of such questions, and the broader gap around audience interaction with the trailer, positioned them as primary research goals of the author's current project.

Our response to existing work, however, helped define part of the project's methodology, particularly around the presenting of data/examples to an audience to be 'rated'. This arose from a consideration of the trailer-specific research project mentioned above. Eastman, Bradbury and Nemes’s (1985) 'Influences of Previews on Movie Viewers' Expectations' compares viewer's expectations of the film Thief (Mann, 1981) based on the associated teaser and trailer. Assessing the expectations of a given trailer potentially generates opportunities for discourse, though the methodological approach focuses instead on the quantitative, applying a numerical value to the audience's experience in order to generate results. The study considers 134 audience members over three nights, each night's cohort viewing a teaser, a trailer or no preview (forming a control group). The findings suggest that seeing any form of audio-visual preview significantly heightens the expectations of a movie and finds little difference between the teaser and the longer trailer (Eastman, Bradbury and Nemes 1985: 56). However, in treating audio-visual materials in isolation from other variable factors that affect cinema-going and comprise the cinema-going experience, the study assesses a (re)constructed cinema-going environment, without observing the possibility of variations to the promotional campaign that may affect decision making. Any assessment of promotional utility must take into account the varied and often subjective context in which they are encountered: in Eastman's research, for example, there is no account of the behaviour of the audience while viewing, so the possibility of interpersonal recommendations is excluded alongside the role of additional promotional materials' impact upon the results. 
On a wider scale, Austin (1981) and Biltereyst, Mathjis and Meers (2008) have conducted surveys that point to the perceived usefulness of trailers on decision making, reinforcing the findings of Eastman et al. However, both present results that rank identified texts in terms of their perceived use, and similar to the Eastman et al. study, separate one source of information from another, removing the possibility of different combinations of promotional materials functioning to the same effect. The Biltereyst, Mathjis and Meers study asked participants to list the three main sources that influenced their decisions prior to viewing. While 'trailers' was ranked second, behind 'Internet/websites' (2008: 51), and the study as a whole opened up a range of materials and divergent data collection practices, the responses were not mutually exclusive and could not explore any possible interplay between each source. For instance, it is unclear whether trailers are viewed online (via 'Internet/websites') in tandem with interpersonal commentary as a shared viewing activity, or shared by social media, offering a prefigurative commentary through the very act of sharing. Despite these limitations, the identified top sources of information correspond with the much earlier and comparatively small-scale work conducted by Austin (1981), and the recent work by Davis et al. (2013), suggesting a longstanding trend in perception that may aid the current project.

Drawing on Austin's initial research, and a hypothesis by Arndt and May (1981), Faber and O’Guinn (1984: 376) speculate that '[p]erhaps previews and television advertising were considered so useful because they provide the viewer with some indication of what the movie will really be like through short excerpts': yet this returns back to an understanding that the trailer will automatically (and perhaps accurately) reflect the film being promoted. Indeed, they compound the limitations of their findings by suggesting that previews have significantly more impact than other sources investigated, and that this 'seems to support the notion that the audience perceives previews as a trial experience on which to base a selection 
decision' (1984: 376). This implicitly suggests that trailers are successful as promotional materials precisely because they reflect the film accurately and are received as such. However, as the introduction suggested, that creates a discrepancy with popular discourse surrounding the trailer that stretches back almost a hundred years.

To paraphrase E. Winthrop Sargent, then, the trailer remains one of the best and most direct forms of promotional activity, no matter what screen is used to target the audience. Whether this is because the trailer looks like the film and operates within the same audiovisual medium remains unclear, and academic opinion on this is divided. Existing research thus provides little information on what audiences think a trailer is, what it does, whether it provides useful or misleading information and what use they can put it to; we do not know where audiences access trailers, whether they share them, or discuss them, or make their own. Given those deficits in current understanding, this project has identified a need to explore the context in which promotional materials are encountered and engaged with. In doing this research, issues such as motivation, objectives and preferences can be explored as well as providing insight into why audiences perceive the trailer as being useful. Previous research has tended towards value attribution that posits single sources of information within a hierarchy, while ignoring the concept that promotional materials may function as part of a social as well as industrial network.

\section{References}

Arndt, J. and May, F. E. (1981), 'The hypothesis of a dominance hierarchy of information sources', Journal of the Academy of Marketing Science, 9: 4, pp. 337-51.

Austin, B. A. (1981), 'Film attendance: Why college students chose to see their most recent film', Journal of Popular Film and Television, 9: 1, pp. 43-49. 
Bacon, Lloyd (1937), Marked Woman, Burbank, CA: Warner Bros.

Biltereyst, D., Mathjis, E. and Meers, P. (2008), 'An avalanche of attention: The prefiguration and reception of The Lord of the Rings', in M. Barker and E. Mathjis (eds), Watching the Lord of the Rings: Tolkien's World Audience's, New York: Peter Lang.

Blandford, S., Grant, B. K. and Hillier, J. (eds) (2001), The Film Studies Dictionary, London: Arnold.

Brachmann, C., Chunpir, H. I., Gennies, S. et al. (2007), 'Automatic generation of movie trailers using ontologies', IMAGE Journal of Interdisciplinary Image Science, 5, pp. 117-139.

Child, B. (2011), 'Woman sues Drive over “misleading” trailer', The Guardian, http://www.theguardian.com/film/2011/oct/10/woman-sues-drive-trailer. Accessed 21 January 2014.

_ (2013), 'Jack Reacher film gives New Zealand viewer too little bang for his buck', The Guardian, http://www.theguardian.com/film/2013/apr/02/jack-reacher-film-new-zealand. Accessed 27 January 2014.

Davis, C. H., Michelle, C., Hight, C. et al. (2013), 'Varieties of prefigurative engagement within The Hobbit's global audience', in International Association for Media and Communication Research Annual Conference, Dublin, Ireland.

D.W.C. (1938), 'Renovating the trailer', New York Times, 10 May, p. 4.

Eastman, S. T., Bradbury, D. E. and Nemes, R. S. (1985), 'Influences of previews on movie expectations', Current Research in Film, 1, pp. 51-57.

Faber, R. J. and O’Guinn, T. C. (1984), 'Effect of media advertising and other sources on movie selection', Journalism Quarterly, 61: 2, pp. 371-77. 
Goldwyn, S. (1951), 'On hollow: Producer warns against ads that mislead', New York Times, 1 April, p. 100.

Gray, J. (2010), Show Sold Separately: Promos, Spoilers and Other Media Paratexts, New York: New York University Press.

Greene, F. (2013), 'Working in the World of propaganda: Early trailers \& modern discourses of social control', Frames Cinema Journal, http://framescinemajournal.com/article/workingin-the-world-of-propaganda-early-trailers-modern-discourses-of-social-control/. Accessed 31 January 2014.

Haralovich, M. B. and Klaprat, C. R. (1981/2), 'Marked Woman and Jezebel: The Spectatorin-the-Trailer', Enclitic, 5-6: 1-2, pp. 66-74.

Hermes, T. and Schultz, C. (2006), ‘Automatic Generation of Hollywood-like Movie Trailers', eCulture Factory. Project overview for eCulture Trends 06 (revised March 12th 2007) http://eculturefactory.de/download/hermes_schulz.pdf Accessed 22 April 2014.

Hesford, D. (2013), ““Action!... Suspense!... Emotion!” The trailer as cinematic performance’, Frames Cinema Journal, http://framescinemajournal.com/article/action-suspense-emotionthe-trailer-as-cinematic-performance/. Accessed 21 January 2014.

Johnston, K. M. (2004), 'Becoming attractions: The history and theory of film trailers, 191639’, Unpublished MA Dissertation, University of Kent.

_ (2008), “The Coolest Way to Watch Movie Trailers in the World”: Trailers in the digital age', Convergence: The International Journal of Research into New Media Technologies, 14: 2, pp. 145-60. 
(2009), Coming Soon: Film Trailers and the Selling of Hollywood Technology, Jefferson, NC: McFarland \& Co. Inc.

Kernan, L. (2004), Coming Attractions, Austin: University of Texas Press.

Konigsberg, I. (1988), The Complete Film Studies Dictionary, London: Bloomsbury.

Lasky, J. (1938), 'The producer makes a plan', in N. Naumberg (ed.), We Make the Movies, London: Faber \& Faber.

Lewis, H. T. (1933), The Motion Picture Industry, New York: D. Van Nostrand Company.

Lienhart, R., Pfeiffer, S. and Effelsberg, W. (1997), 'Video abstracting', Communications of the ACM, 40: 12, pp. 54-62.

Maier, C. D. (2009), 'Visual evaluation in film trailers', Visual Communication, 8: 2, pp. $159-80$.

Mann, Michael (1981), Thief, Beverly Hills, CA: United Artists.

Medhurst, A. (1998), 'The big tease', Sight \& Sound, 8: 7, pp. 24-26.

Ontario Regulation 425/05 (2005), 'Film Classification Act', http://www.elaws.gov.on.ca/html/regs/english/elaws_regs_050452_e.htm. Accessed 21 January 2014.

Sargent, E. Winthrop (1915), Picture Theatre Advertising, New York: The Moving Picture World, Chalmers Publishing Co.

‘Selznick Has Clever Trailer' (1917), Moving Picture World, 33: 3, p. 663.

'Specialised Techniques in Trailer Production' (1938), The Cinema, 51: 4034, p. 11.

Staiger, J. (1990), 'Announcing wares, winning patrons, voicing ideals: Thinking about the history and theory of film advertising', History, 29: 3, pp. 3-31. 
Thompson, H. (1937), 'Trailer stupidity', Film Weekly, 18: 453, pp. 7, 9, 14.

Vollans, E. (2013), 'Trailers are following me: Studying contemporary “trailers", Recorded at Media Mutations 5, May 21, Bologna, Italy, http://archivi.dar.unibo.it/index.php/archivivideo/conferenze/mediamutations/mediamutations-5/. Accessed 31 January 2014.

Williams, K. (2009), 'Never coming to a theatre near you: Recut film trailers,' M/C Journal, 12: 2, http://journal.media-culture.org.au/index.php/mcjournal/article/viewArticle/139. Accessed 21 January 2014.

Yousry, M. M. (2010), 'Going to the movies in Egypt', Kinema, http://www.kinema.uwaterloo.ca/article.php?id=468\&feature. Accessed 21 January 2014.

\section{Contributor details}

Frederick Greene, Ph.D. (English Literature, UCSB, 1997), is a visiting assistant professor within UCLA's Department of Film, Theater and Television. Writer, research and coproducer of Coming Attractions: A History of the Movie Trailer, Greene is a copywriter serving the entertainment industry. He has lectured on trailers and the history of movie marketing at the Academy of Motion Pictures Arts and Sciences, NYU and Pasadena's Arts Center.

Contact: Frederick Greene, 7052 3/4 Hawthorn Ave., Los Angeles, CA 90028

Tel.: (1) 3236830603

E-mail: flgreene@yahoo.com

Blog: www.movietrailers101.com

Dr Keith M. Johnston is Senior Lecturer in Film \& Television at the University of East Anglia. He is the author of Coming Soon: Film Trailers and the Selling of Hollywood Technology (2009) and Science Fiction Film: A Critical Introduction (2011), and is the key institutional lead for the annual international 3DS conference and Norwich Sound + Vision festival. His research interests include promotional materials (with a particular interest in trailers), stereoscopic 3D media, genre, media technology and cross-media interactions.

Contact: Dr Keith M. Johnston, School of Film, Television and Media Studies, University of East Anglia, Norwich Research Park, Norfolk UK, NR4 7TJ 
E-mail: keith.johnston@uea.ac.uk

Work blog: www.keithmjohnston.blogspot.com

Ed Vollans is a final year Doctoral Candidate at the University of East Anglia, under the supervision of Dr Keith M. Johnston. He holds a Masters from the University of Edinburgh, is a Fellow of the Royal Society of the Arts and has previously worked as a Film Industry Journalist in Mumbai. His doctoral thesis explores the use of trailers across different entertainment industries and the on-going changes to the use and reception of trailers.

Contact: Ed Vollans, School of Film, Television and Media Studies, University of East Anglia, Norwich Research Park, Norfolk UK, NR4 7TJ

E-mail: e.vollans@uea.ac.uk

\footnotetext{
${ }^{1}$ While parallel work in computing, notably the creation of automatic trailer generation systems (cf. Lienhart, Pfeiffer and Effelsberg 1997; Brachmann et al. 2007; Hermes and Schultz 2006), implied that trailers could be reduced to codified objects within which an optimum narrative was organized, the scientists involved in one such project noted that while they were interested in 'how close algorithms could get to this goal' of producing a trailer, the trailers was 'a piece of art produced by creative humans' (Johnston 2009: 214).
} 